\title{
ESTUDIOS PREVIOS PARA LA RESTAURACIÓN DE LA AZOTEA DE LA CASA MILÀ DE BARCELONA (CATALUÑA, ESPAÑA)
}

\author{
(STUDIES PRECEDING THE RESTORATION OF THE CASA MILÀ OF \\ BARCELONA. CATALONIA, SPAIN)
}

Raquel Lacuesta Contreras, historiadora del arte

Miembro de la Academia del Partal (Asociación Libre de Profesionales de la Fecha de recepción: 10 - XII - 93 Restauración Monumental)

\section{RESUMEN}

La Casa Milà de Barcelona, obra del arquitecto Antoni Gaudí construida entre 1906 y 1911, fue adquirida en 1986 por la Caixa de Catalunya que a partir de entonces inició un proceso de restauración del edificio. Una de las fases de la intervención consistirá en restaurar la azotea con todos los elementos arquitectónicos-escultóricos que contiene (cajas de escalera, chimeneas, torres de ventilación y pasos de ronda). A tal fin, se han realizado unos estudios previos que contemplan los aspectos histórico-constructivos, documental y artístico de todos estos elementos, y también una propuesta de actuación a tener en cuenta en el proyecto de restauración.

\section{SUMMARY}

The Casa Milà of Barcelona, work of the architect Antoni Gaudi, built between 1906 and 1911, was purchased in 1986 by the Caixa de Catalunya which then started a process of restoration of the building. One of the stages of this intervention will consist of restoring the roof with all the architecturalsculptural elements it contains (the staircase boxes, chimneys, ventilation towers and perimetral paths). A number of previous studies have been done to this end. They deal with the historicalconstructive, documentary and artistic aspects of all these elements as well as with an action proposal to be taken into account in the restoration project.
La idea de hacer unos estudios previos para la restauración de la azotea de la casa Milà de Barcelona (obra del arquitecto Antoni Gaudí, popularmente conocida como "la Pedrera"), pero en especial de los elementos arquitectónico-escultóricos que la monumentalizan, surgió de la intención que la Caja de Ahorros de Cataluña, propietaria del inmueble, tenía de actuar en este sector del edificio, como continuación de las obras de restauración iniciadas en 1987 y dirigidas por los arquitectos barceloneses José Emilio Hernández Cros y Rafael Vila Rodríguez.

\section{Objetivos y metodología previa}

Estos estudios, realizados en 1992, tenían dos objetivos prioritarios: por un lado, el análisis históricoconstructivo y artístico de cada uno de los elementos que se levantan sobre la azotea y de las intervenciones o reparaciones que se produjeron en ellos a lo largo de este siglo; por otra parte, servir de instrumento documental para emprender la restauración de estos elementos.

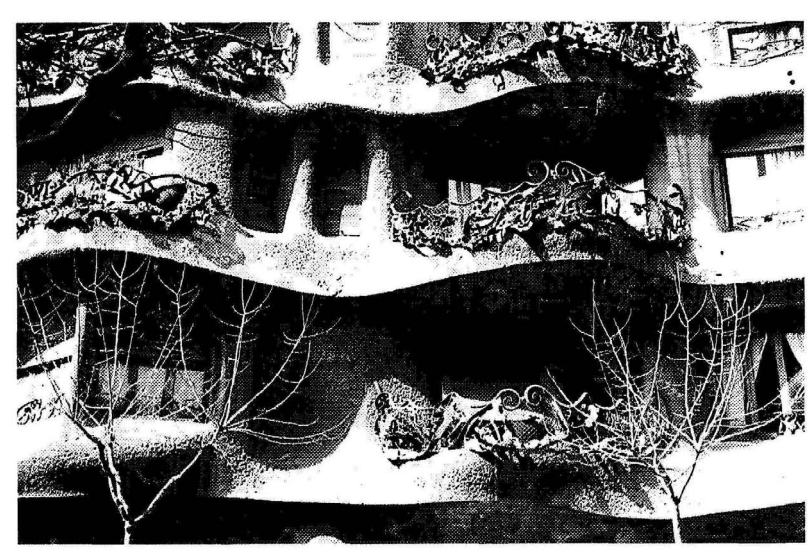

Fachada de la Casa Milà. (Foto Arxiu GMN, 1961) 


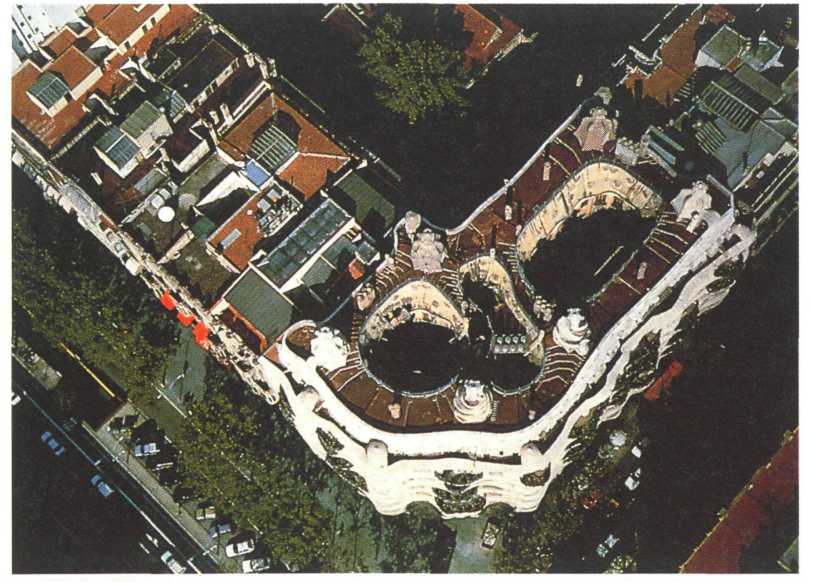

Vista aérea de la Casa Milà. Foto: PAVISA, 1992.

Cuando Gaudí acabó la Casa Milà en 1911, sólo emergían de la azotea 6 cajas de escalera, 2 torres de ventilación y 7 chimeneas sencillas o compuestas y 4 cupulines situados sobre el paso de ronda accesible desde la planta de los desvanes. Todos estos elementos se conservan, pero acompañados, actualmente, de 16 chimeneas más que fueron surgiendo a medida que se operaban reformas en el interior de los pisos, algunas de las cuales, pese a su construcción relativamente reciente, habían pasado ya a la memoria colectiva como obra de Gaudí.

Para la elaboración del trabajo, además de la necesaria consulta bibliográfica, se recurrió a la documentación fotográfica existente en los archivos más antiguos, con el fin de reconstruir la historia, paso a paso, de aquellos elementos, a la vez funcionales y escultóricos. De hecho, la bibliografía reproducía una y otra vez fotografías con los mismos o parecidos puntos de vista, con comentarios casi siempre interpretativos del mensaje de Gaudí, literatura más o menos recreada y fantástica, pero poco útil para el trabajo que se pretendía llevar a cabo.

Una vez recopiladas todas las fotografías de archivo o las que aportaban algunos datos nuevos en la bibliografía consultada, se realizó un reportaje tomando los mismos puntos de vista y estableciendo una comparación cronológica para averiguar cuándo y por qué se habían edificado nuevos elementos, y qué alteraciones o cambios habían tenido los genuinamente gaudinianos.

Determinar los materiales de revestimiento de algunos edículos y su tonalidad a través de viejas imágenes presentó cierta dificultad, ya que hasta finales de los 60 no se habían publicado fotografías en color que permitieran conocer exactamente el acabado ori- ginal. El blanco y negro sugería acabados de estuco, a veces, o de pintura sobre-probablemente- revoco, y, al menos, tres gamas de colores. También se detectaban en algunas fotografías reparaciones $-\mathrm{O}$ mejor, mutilaciones-, que podían indicar una eliminación del revoco original, con lo cual el análisis de los morteros en la actualidad no aportaría ningún dato a la historia del revestimiento.

\section{Evolución histórica de los elementos}

A grandes rasgos, la reconstrucción de la pequeña historia de los edículos de la azotea de la Casa Milà es la siguiente:

En 1910, Gaudí había acabado casi por completo las obras; sólo faltaban por colocar las barandillas de protección que rodean los dos patios interiores del edificio y un tercer patio de luces, e instalar los vidrios de los lunetos de las salidas de las seis cajas de escalera.

De éstas, cuatro presentaban revestimiento de trencadís o fragmentos planos de formas irregulares de piedra, mármol o azulejo, y dos se hallaban revoca-
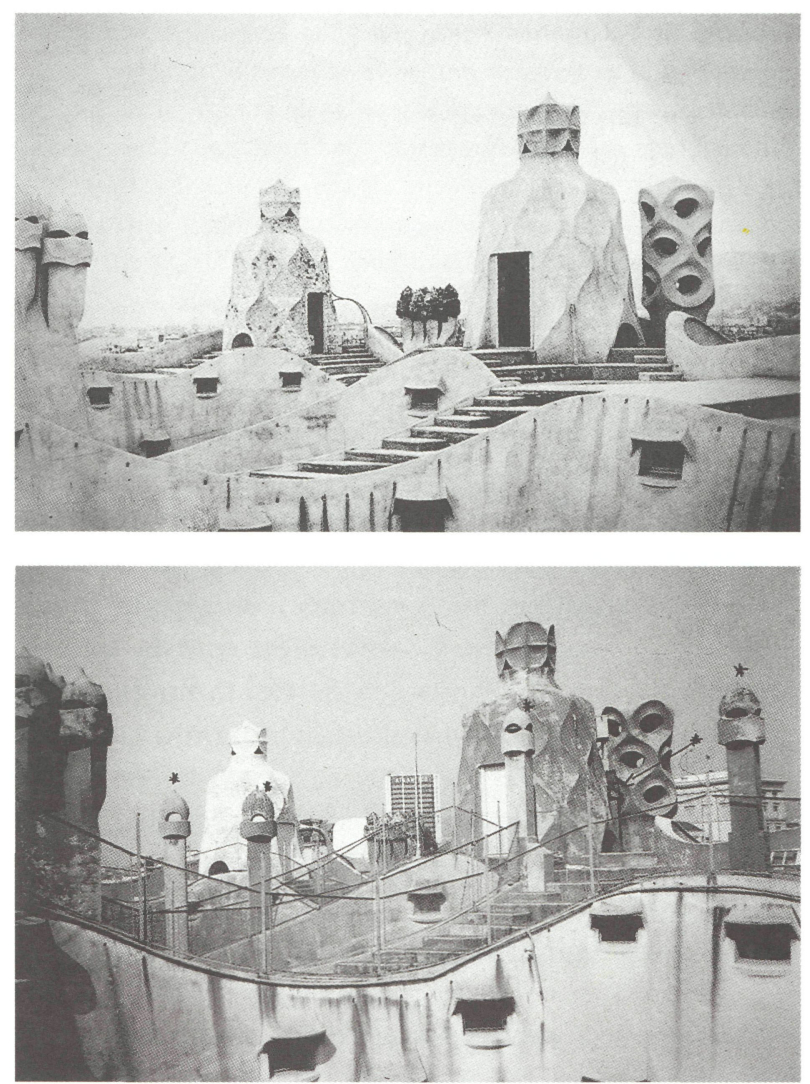

Arriba, la azotea en 1910, antes de colocar las barandillas de protección. Foto: Centro Excursionista de Cataluña. Abajo, la misma vista tomada en 1992, con las chimeneas construidas en 1954. Foto: Raquel Lacuesta. 


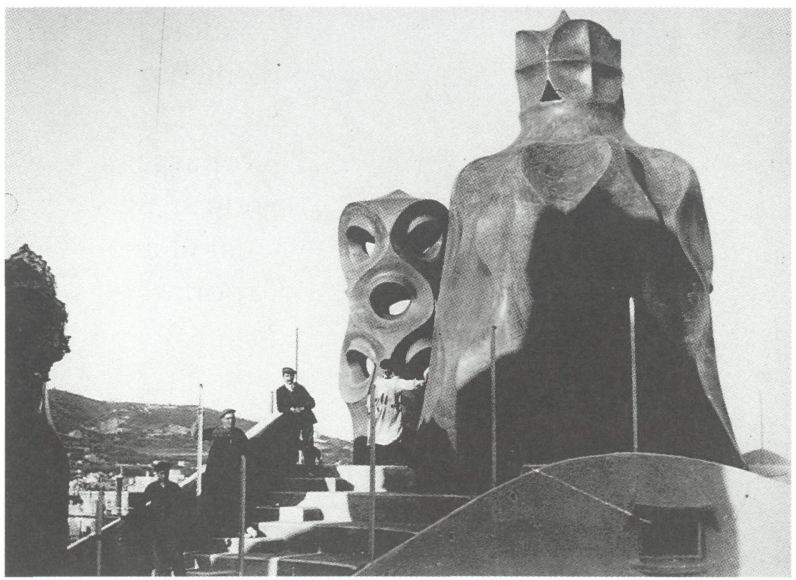

La salida de la caja de escalera $n^{\circ} 6$ y la torre de ventilación $n^{\circ} 1$, en 1911. Foto Archivo GMN.

das y enlucidas. Las dos torres de ventilación y las siete chimeneas también tenían un acabado de enlucido, excepto una de ellas, ramificada y coronada con seis sombreretes revestidos con fragmentos de vidrios de botellas de champagne. Por último, los cuatro cupulines ya se mostraban recubiertos de trencadis de mármol y piedra.

En fotografías de 1927, aparecían dos nuevas chimeneas conectadas a través de los patios con los primeros pisos. De forma mucho más sencilla y peor acabado que las diseñadas por Gaudí, pero todavía con cierta intención mimética, presentaban un revestimiento o enlucido igual al de los patios. Algunos sombreretes de las chimeneas ya habían sufrido alguna agresión poco respetuosa, debido probablemente a reparaciones del tiro de humos.

Entre 1927 y 1954, la mayor parte de las construcciones emergentes que no tenían la protección del trencadís presentaban un estado de conservación lamen-

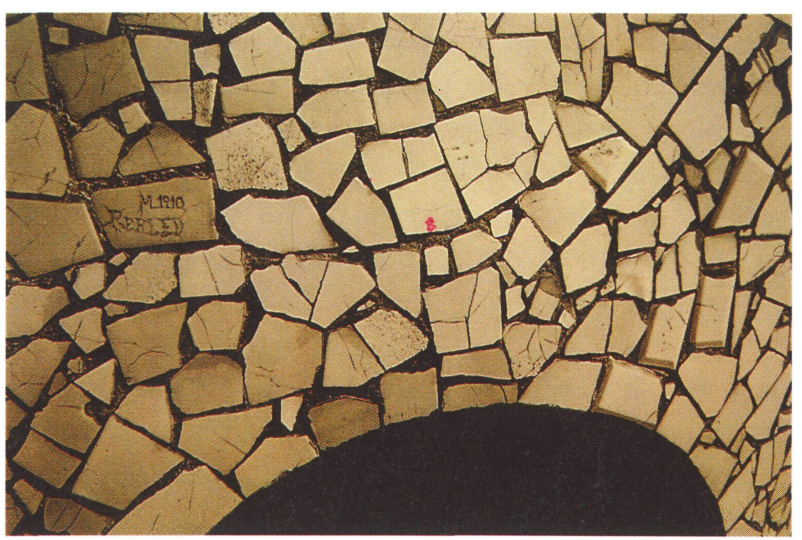

Revestimiento de "trencadís" (fragmentos de material cerámico $y$ pétreo), en la caja de escalera $n^{\circ} 2$. Foto: Raquel Lacuesta.

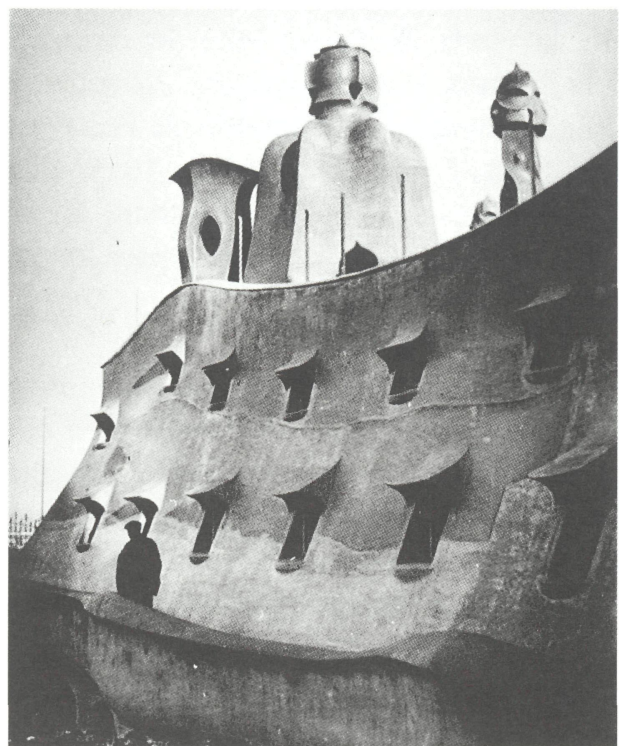

Conjunto de la caja de escalera $n^{-} 5$, la torre de ventilación $n^{\circ} 2$ y la chimenea $n^{\circ}$ 9, en 1911. Foto Archivo GMN.

table; también se detectan modificaciones groseras en los sombreretes de otras chimeneas, revocos parciales y desaparición de algunos relieves decorativos, lo que hace pensar en actuaciones no controladas por un técnico. Hay que tener en cuenta que la azotea de la Casa Milà, a pesar de su carácter monumental, no estaba pensada para otra cosa que no fuera la de tender la ropa, y sus majestuosos edículos eran, ante todo, extractores de aire y de humo.

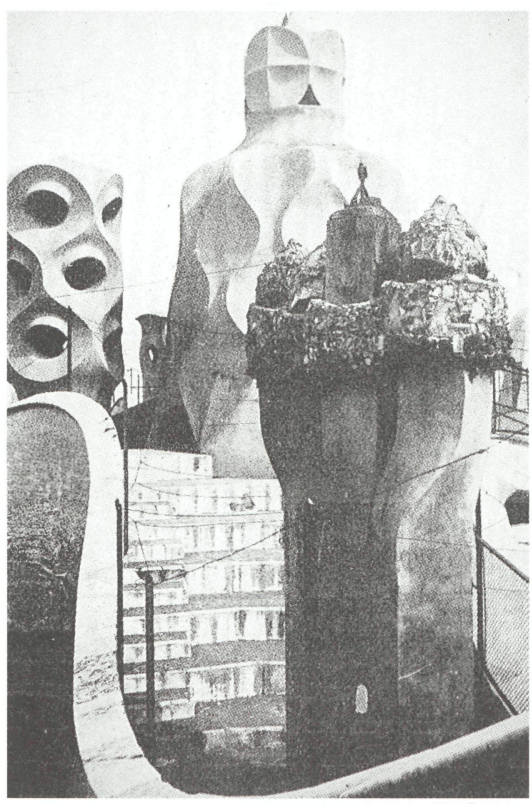

Aspecto que presentaba la chimenea $n^{2} 16 \mathrm{en}$ 1929, con uno de los sombreretes modificados Foto procedente del libro Gaudi, de J.F. Rafols. 
En 1946, la viuda de Pedro Milà, Rosario Segimón, vendió la Pedrera a la Inmobiliaria Provenza, que no tardó mucho tiempo en rentabilizar como fuese su nueva propiedad. Así, entre 1954 y 1955, encargó al arquitecto Francisco Juan Barba Corsini un proyecto de remodelación de los desvanes para convertirlos en apartamentos de alquiler.

Estos apartamentos, con sus correspondientes baños, cocinas y hogares, obligaron a levantar en el terrado un total de 14 chimeneas nuevas, para dirigir los humos o para ventilar, que se hicieron aisladas o conectadas a los lunetos de las cajas de escaleras o a los conductos de las que ya existían. Algunas de ellas, las que habían de ser visibles desde la calle, adoptaron formas gaudinianas, repitiendo o copiando a escala igual o menor algunos de los edículos existentes, e incluso los revestimientos pétreos o revocados. Las más interiores fueron realizadas con mucho menos sentido artístico y sólo sus sombreretes recuerdan lejanamente las que Gaudí había proyectado y que habían sido modeladas previamente en yeso por el escultor Joan Beltran. No se tocaron, sin embargo, las chimeneas de Gaudí, que progresivamente se iban deteriorando.

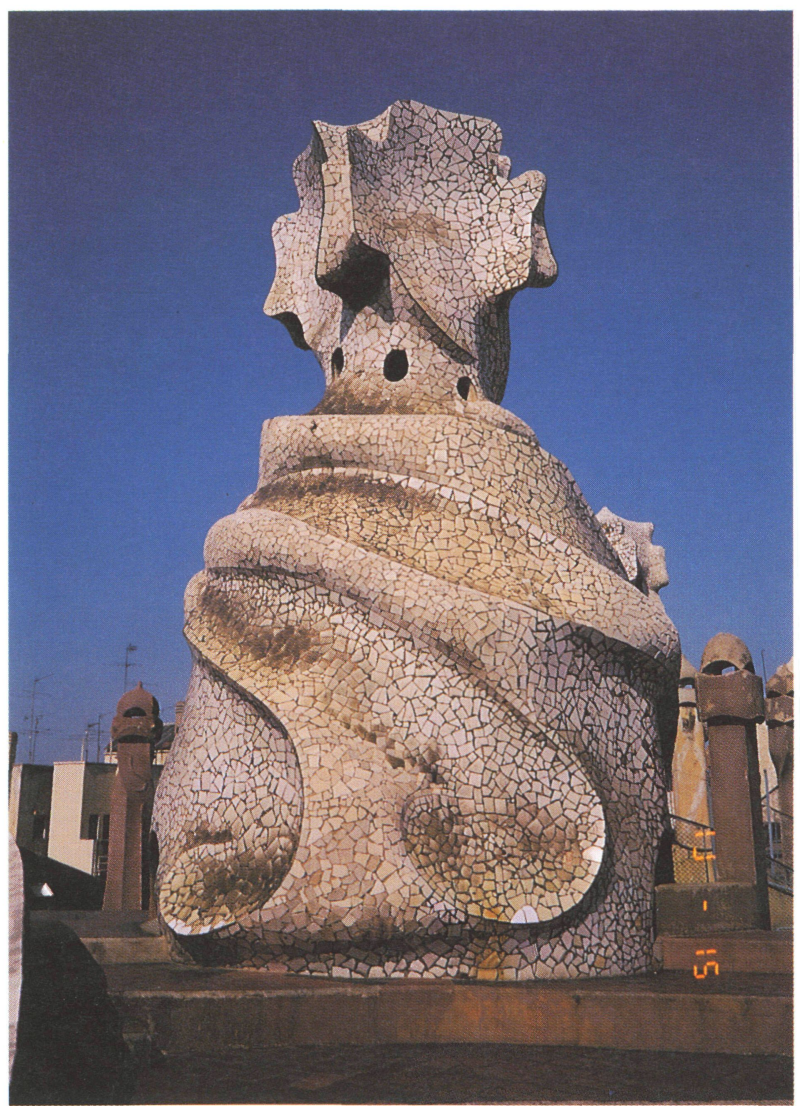

A cada lado de la caja de escalera $n^{\circ} 2$ se pueden ver algunas de las chimeneas construidas en 1954. cuando el desván fue transformado en apartamentos. Foto: Raquel Lacuesta, 1992.

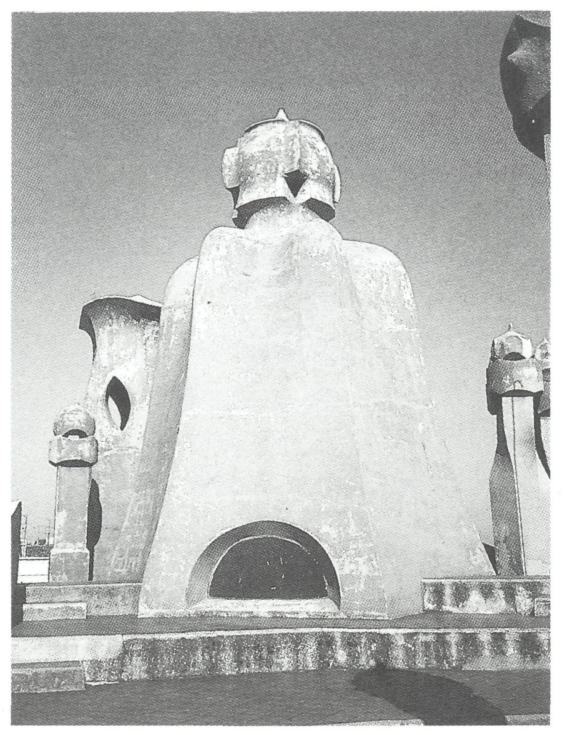

Entre 1972 y 1975, con motivo de unas obras de restauración de la fachada de la casa Milà, los elementos de la azotea que no estaban revestidos de "trencadis" fueron pintados de color marrón rojizo. Foto: R. Lacuesta, 1992.

Entre 1971 y 1975, por fin, a causa del desprendimiento de unos fragmentos de piedra de la fachada principal, que cayeron a la calle en octubre de 1970, se emprendieron obras de restauración, las cuales fueron dirigidas por el arquitecto José Antonio Comas de Mendoza. En aquel momento, la azotea y sus edículos estaban en un avanzado grado de deterioro. Los revocos y enlucidos estaban agrietados y en parte desprendidos de la fábrica de ladrillo y algunos sombreretes dejaban ver los perfiles metálicos estructurales totalmente descarnados.

Aprovechando las obras de restauración, se decidió hacer algunas reparaciones, que consistieron fundamentalmente en revocar de nuevo los elementos que no tenían revestimientos pétreos o cerámicos (ya que éstos eran los únicos que se mantenían en buen estado de conservación), en restituir a la forma casi original los sombreretes que habían sido modificados tiempo atrás y en aplicar pintura marrón rojiza, entonces tan a la moda, perdiendo con ello el acabado original de revoco y enlucido que había proporcionado a estos elementos una textura y un brillo propios del estuco planchado. No se extrajeron, en cambio, los tubos, depósitos, cables y demás objetos que se habían ido empotrando en sus paredes a lo largo del tiempo.

En 1986, la Caixa de Catalunya adquirió el inmueble; la azotea, que hasta entonces había sido utilizada únicamente por los vecinos y visitada sólo con la correspondiente autorización, perdió su uso original y se convirtió en una de las zonas visitables por el público. De ahí la necesidad de su restauración. 


\section{Análisis constructivo de los edículos}

Para el análisis de todos y cada uno de los elementos emergentes de la azotea aplicamos una metodología semejante a la que un año antes habíamos utilizado en el Servicio del Patrimonio Arquitectónico de la Diputación de Barcelona para las chimeneas revestidas de trencadís del Palau Güell, obra también de Antoni Gaudí, en la misma ciudad de Barcelona. A partir de una ficha tipo, se definieron una serie de conceptos a desarrollar en función de las características de cada elemento.

Era necesario, al mismo tiempo, realizar un levantamiento de planos del terrado, que no se había hecho nunca: así, se levantó una planta general y una cenital, y también plantas, alzados y secciones de los edículos. Con ello se facilitaba el estudio del sistema constructivo, obtener medidas de cada elemento y proceder a su situación en planta con la numeración que previamente les habíamos dado para su agrupación tipológica. Este levantamiento fue ejecutado por la empresa CAD Quatre, de Barcelona, bajo la dirección de Xavier Perarnau. El sistema utilizado en la toma de datos y su posterior elaboración se realizó siguiendo un procedimiento complejo que consistió en una combinación de técnicas de topografía, sistemas de CAD y procesado digital de imagen fotográfi$\mathrm{ca}$, con lo que se obtuvieron unos resultados muy similares al de la fotogrametría.
La ficha tipo no se ajustó a un modelo esquemático cerrado, sino que se optó por crear campos abiertos para desarrollar con todo detalle el contenido de cada concepto, ya que el repertorio de formas, composición y revestimientos era menos variado y complejo y, en muchos casos, repetitivo.

Los conceptos desarrollados se definieron en función de la descripción volumétrica de cada elemento, el sistema constructivo, los materiales de revestimiento, el análisis compositivo, la fecha de construcción, las restauraciones efectuadas, las referencias documentales en las que se basaba el estudio individualizado, el estado de conservación y las propuestas de actuación de cara a la futura restauración.

En total, los elementos de estudio fueron 35. El sistema constructivo es igual para todos ellos, a base de paredes y bóvedas a la catalana hechas con ladrillos y rasillas enteros o fragmentados, con uno o dos gruesos según las zonas, y unidos con mortero de cal, que adoptan formas geométricas diversas (parabólicas, helicoidales, troncopiramidales o troncocónicas). Por el exterior, originalmente estaban enfoscados y enlucidos también con mortero de cal. De todos los elementos construidos por Gaudí, sólo cuatro cajas de escalera y los cuatro cupulines fueron revestidos con fragmentos de piedra, mármol o cerámica esmaltada. El resto fue dejado con el acabado propio del enlucido.

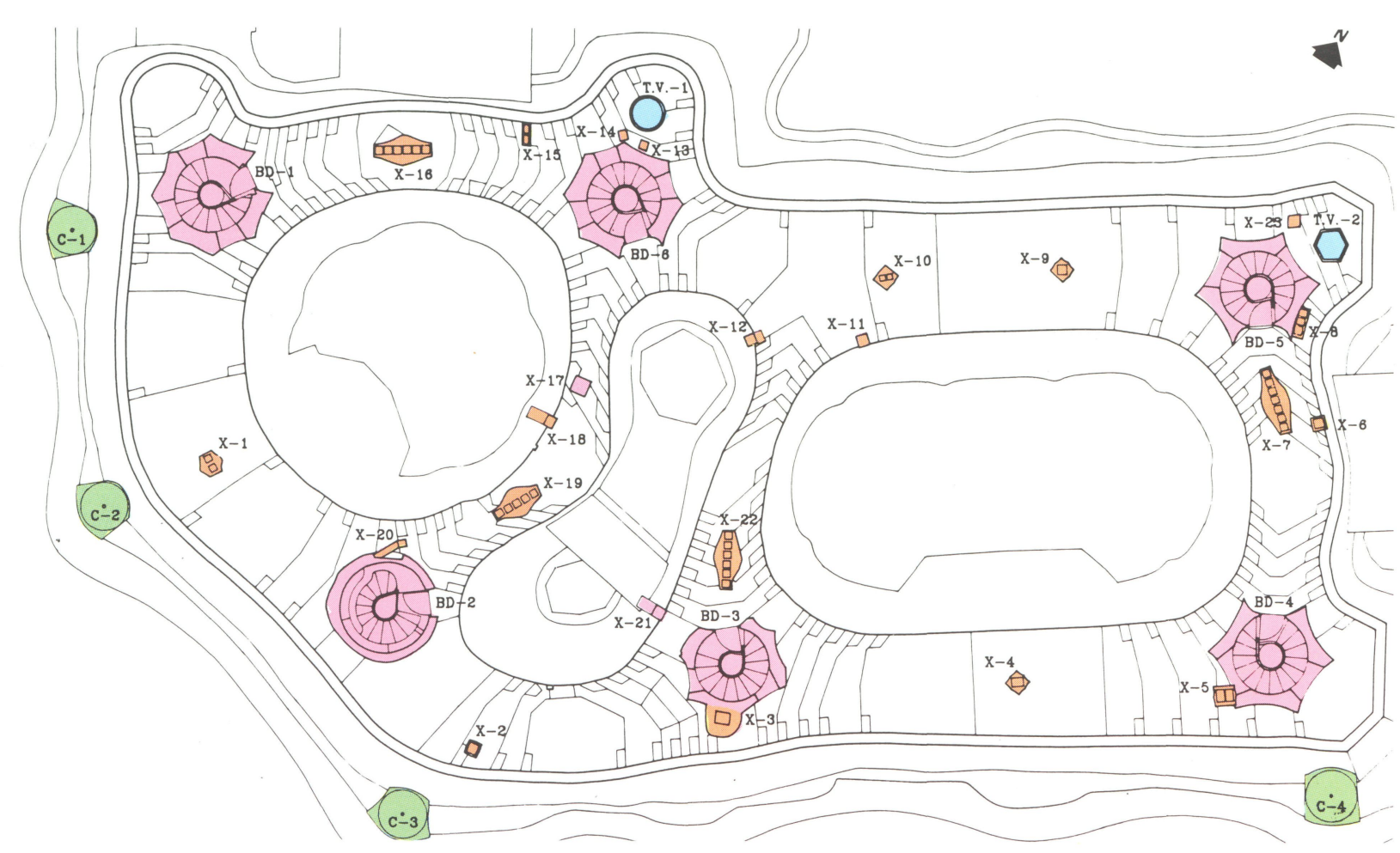

Planta de la azotea, en su estado actual. El levantamiento de planos fue realizado por el equipo CAD QUATRE, de Barcelona, 1992. 
Las cajas de escaleras se levantan sobre una base cilíndrica de doble grueso de ladrillo ordinario, que tiene el punto de arranque en la planta de los desvanes y que contiene una escalera de caracol de obra y acabada con cemento y un perfil metálico en el borde del escalón. Este cuerpo se apoya en haces radiales de vigas de hierro. La escalera circunda en su recorrido otro cuerpo cilíndrico, también de ladrillo, que da cabida a un depósito de agua soportado por una solera. Por el interior, la caja está cubierta con una bóveda parabólica de revolución, tabicada, construida en hiladas concéntricas de ladrillo, en cuyo punto más alto se abre para dar paso al cuerpo o árbol central de la escalera que sirve de base al "sombrerete" que corona cada edículo (en cuatro casos son cruces y en dos unos cuerpos pseudocilíndricos). Estos sombreretes tienen un ánima o esqueleto metálico, están revocados por el interior y reproducen las formas, en negativo, del exterior. Los paramentos inclinados exteriores están resueltos con muretes de tabiques colocados perpendicularmente al paramento y después recortados para adaptarlos a las líneas sinuosas definitivas, sobre las cuales se apoyan las bóvedas tabicadas que dan forma a cada edículo.

Las dos torres de ventilación están construidas con dos gruesos de rasilla colocada a juntas encontradas, aunque fragmentada para facilitar el juego circular. En el caso de la torre número 1, las formas lemniscatas de la linterna se consiguen mediante la construcción de hojas de bóvedas tabicadas, también de dos gruesos. Los huecos de ventilación, construidos con el mismo sistema, forman un arco abocinado por la parte superior. La cubierta se apoya en una solera sostenida por dos $\mathrm{T}$ de hierro paralelas. En el caso de la torre número 2 , la cubierta es una bóveda tabicada y, en el interior, forma una solera reforzada con una doble $\mathrm{T}$ metálica.

Todas las chimeneas de la azotea, tanto las diseñadas por Gaudí como las que diseñó más tarde Barba Corsini, están construidas siguiendo el mismo sistema que el resto de los edículos: a base de rasillas colocadas a juntas encontradas, de uno o dos gruesos, según las zonas, y unidas con mortero de cal o cemento (las más modernas). Los sombreretes forman también bóvedas tabicadas sin ningún refuerzo metálico interior. Algunas chimeneas son sencillas, formadas por un tronco, una rama y un sombrerete (dos de ellas diseñadas por Gaudí y la mayoría restante por Barba Corsini), y otras compuestas, es decir, a partir de un tronco común se ramifican en dos, cinco, seis y siete brazos, cada uno con su correspondiente sombrerete (todas éstas hechas por Gaudí).
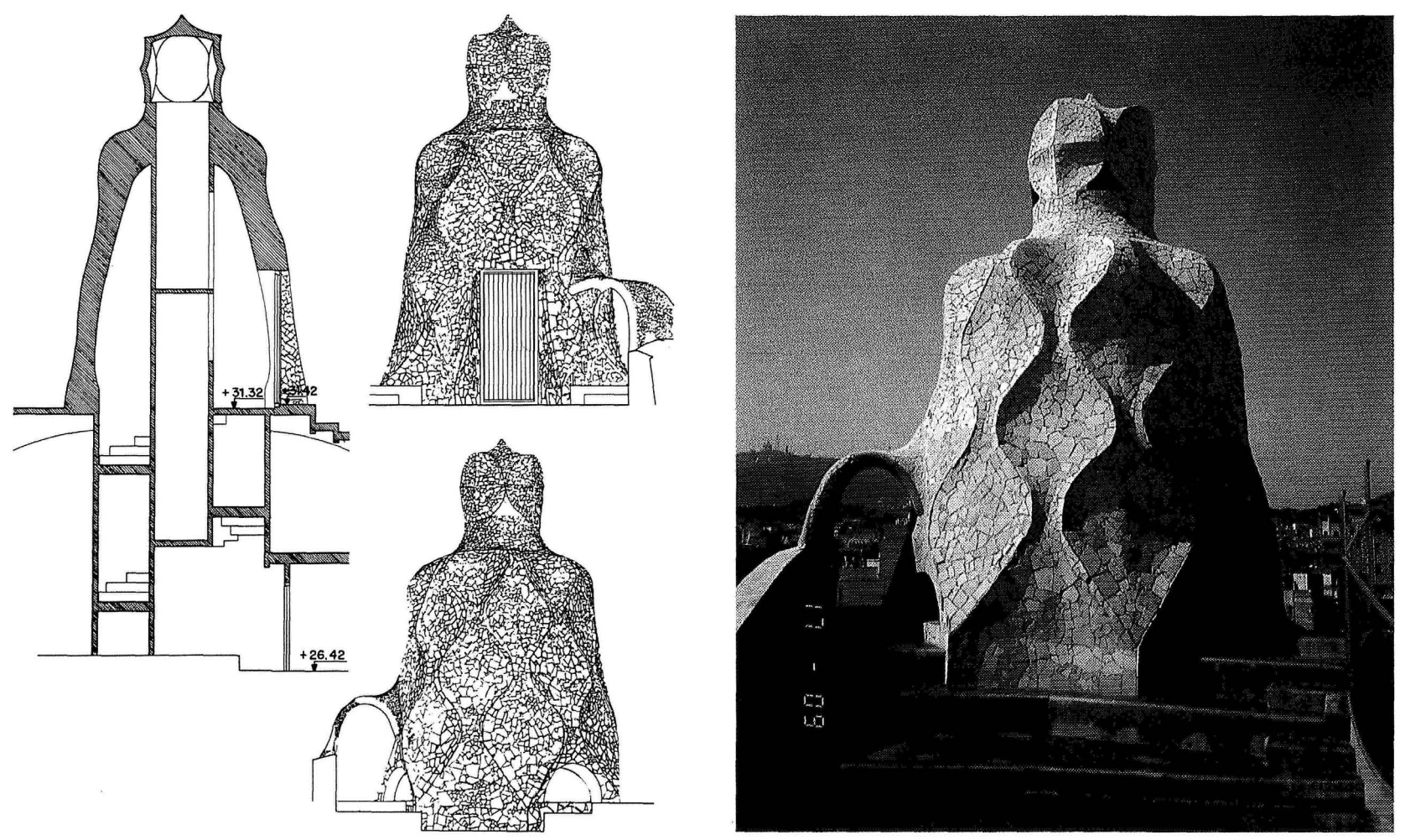

Caja de escalera no 1, en su estado actual. Sección y alzados. Foto: R. Lacuesta, 1992. 

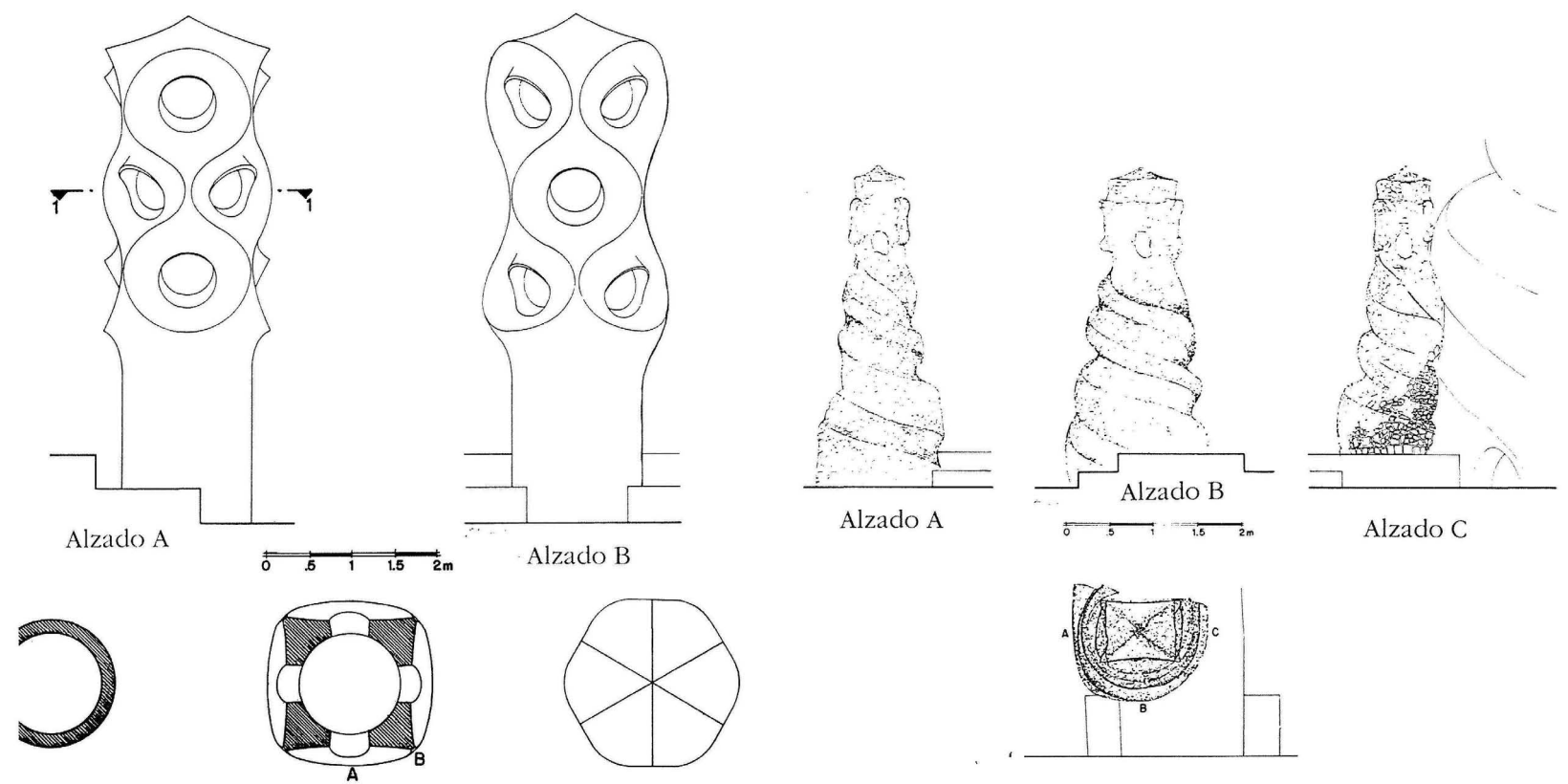

Alzados y plantas de la torre de ventilación $n^{\circ}$ 1, 1992.

Chimenea $n^{0} 3$, diseñada por Barba Corsini. Alzados y planta, 1992.
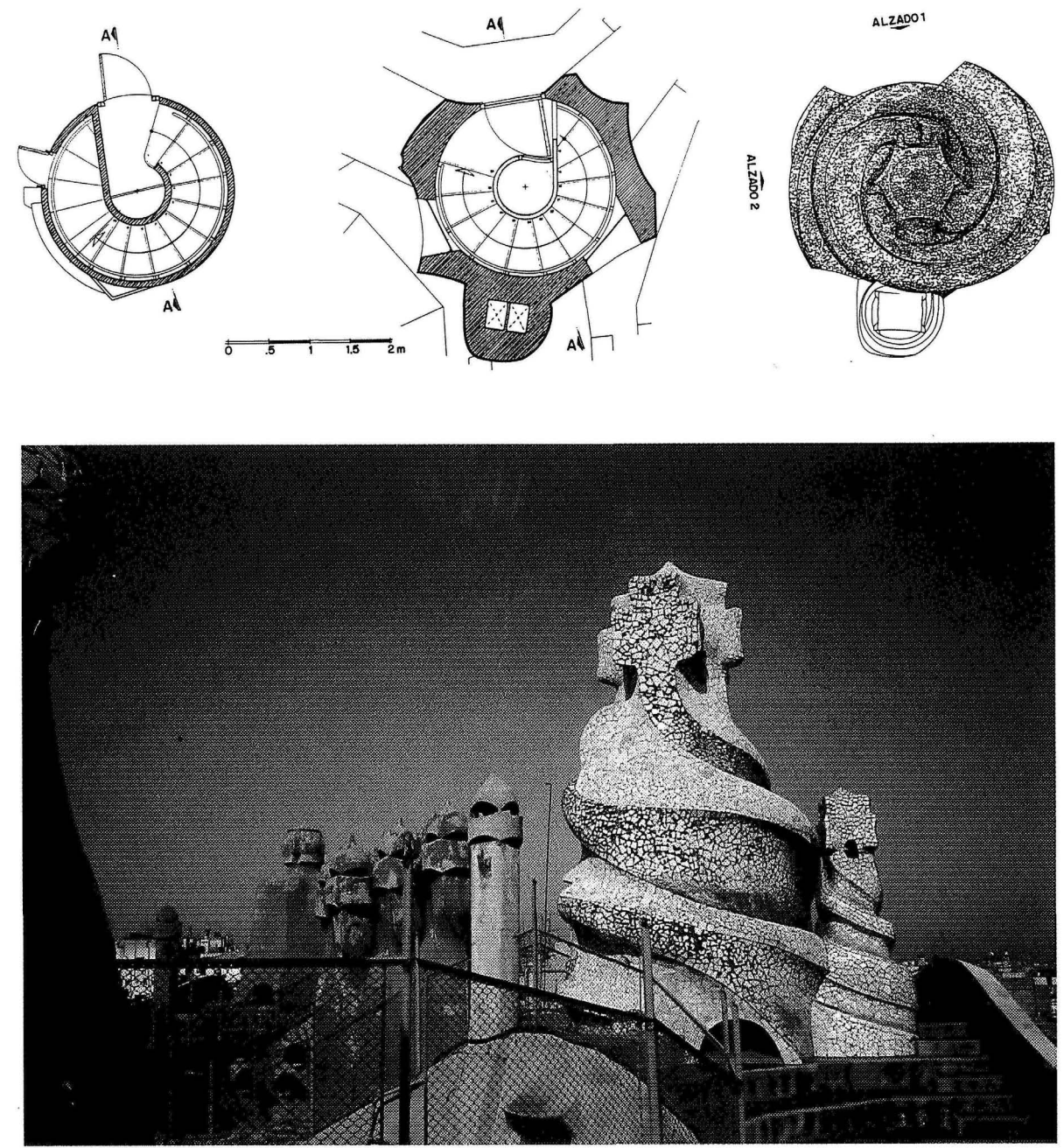

Caja de escalera $n^{\circ} 3$, en su estado actual y plantas. La chimenea que se le adosa fue construida por el arquitecto Barba Corsini en 1954. Foto: R. Lacuesta, 1992.

(c) Consejo Superior de Investigaciones Científicas 
En cuanto a los cuatro cupulines situados en el paso de ronda de la planta de los desvanes y que constituyen una especie de porche cubierto que protege las puertas de salida, están construidos con una bóveda parabólica tabicada y dos arcos, también

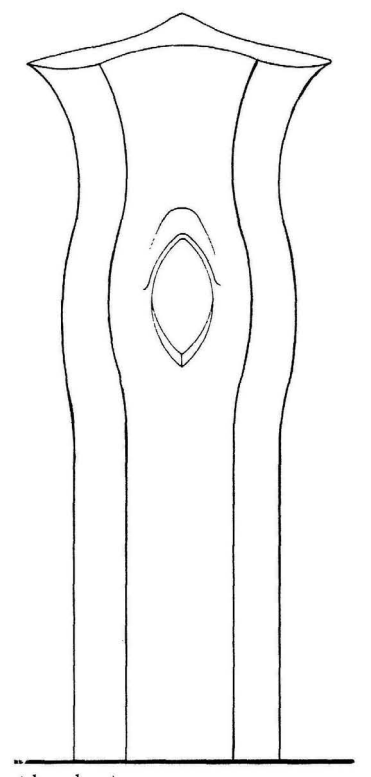

Alzado A

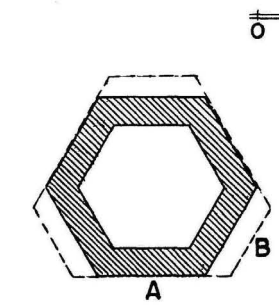

Planta de terraza

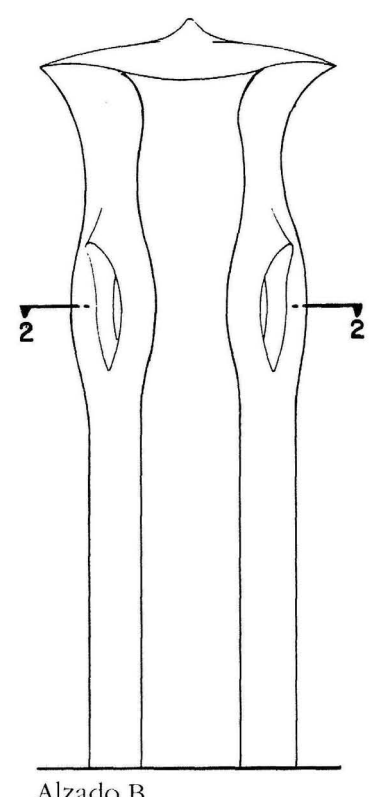

Alzado B
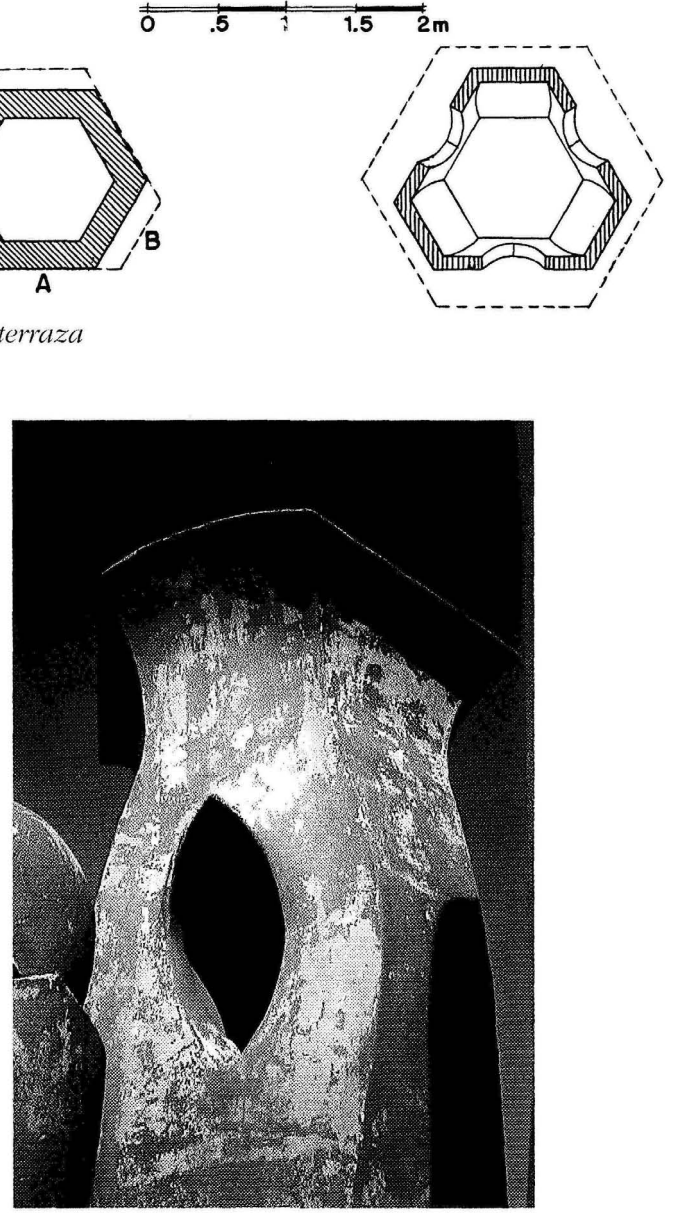

Estado actual, alzado y plantas de la torre de ventilación $n^{2} 2.1992$. parabólicos, realizados con un perfil metálico. Por el interior están enfoscados y por el exterior recubiertos de trencadís de mármol.

\section{El revestimiento exterior}

Los revestimientos de trencadís ya los había utilizado Gaudí en obras anteriores, como en el palacio y en el parque Güell, en donde recreó composiciones polícromas y efectos pictóricos muy diferentes de los que diseñó, más tarde, para la Pedrera. Aquí, la gama es prácticamente monocroma, con sutiles matices en las tonalidades, que van del blanco al gris y del blanco amarillento al beige, sin apenas alejarse del tratamiento cromático de las fachadas exteriores y de los patios interiores. Las diferentes clases de piedra que se aplican en el trencadís proceden, en general, de restos de la misma obra y los azulejos, blancos lisos o de colores pastel, procedían de Onda $\mathrm{y}$, en general, eran de desecho.

El análisis científico del material pétreo se llevó a cabo en el Departamento de Cristalografía de la Facultad de Geología de la Universidad de Barcelona, bajo la dirección del profesor Màrius Vendrell. También colaboró el marmolista Josep Miret. El objetivo de este análisis era determinar las características petrológicas de las diferentes clases de fragmentos que revisten los edículos y conocer su origen. Para ello se obtuvieron láminas delgadas de unas 30 micras de grosor, que fueron estudiadas mediante microscopía óptica de polarización. Esta técnica permite identificar la composición mineral y

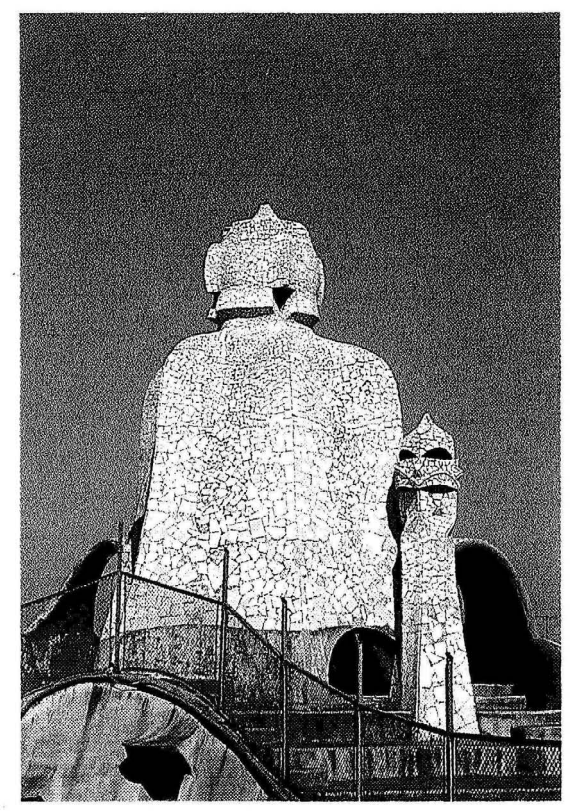

Caja de escalera $n^{\circ} 4$, de Antoni Gaudi, y chimenea $n^{\circ} 5$, realizada por Barba Corsini en 1954. Foto: R. Lacuesta, 1992. 
determinar su textura, que pueden ser comparadas con las correspondientes rocas de explotaciones conocidas y relacionarlas para saber su procedencia.

Como en el Palau Güell, Gaudí utiliza fragmentos de mármol del país y de Carrara, y también de vidrio: pero en el caso de la Pedrera, se trata de vidrios rotos de botellas de color verde incrustados en mortero, con lo cual la superficie que se obtiene es de formas redondeadas y abultadas.

De las seis cajas de escalera existentes, hay cuatro modelos distintos y dos repetidos. Los cuatro primeros se alinean a lo largo de la fachada y son los que están revestidos con material pétreo y cerámico. El trencadís juega un importante papel en la composición de las formas y en la creación de efectos de clarobscuro.

En la caja de escalera número 1, las formas lemniscatas o alveolares se desdoblan en franjas verticales alternas con una sutil diferencia en el tratamiento cromático, que viene dada por el cambio de material: unas están recubiertas con fragmentos de piedra caliza de Ulldecona, en las variantes de Cenia, Chert y Borriol, y las otras son variantes de Carrara, Macael y Tranco.

Los colores y la textura originales se han ido perdiendo por efectos de la erosión y la contaminación ambiental, aunque se ha podido comprobar que estos fragmentos o losetas nunca estuvieron pulidos, sino solamente afinados con sierra manual por las dos caras. La gama cromática, que en un principio variaba del beige amarillento al rosado y al blanco marmóreo, hoy se presenta prácticamente invertida, ante la respuesta que las diferentes clases de piedra han tenido con el contacto exterior: los tonos beiges

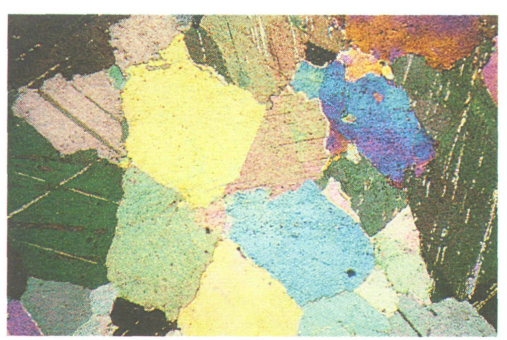

El análisis científico de los materiales pétreos del "trencadís" se realizó en el Departamento de Cristalografía de la Facultad de Geología de la Universidad de Barcelona. Detalle de un fragmento de mármol del país, tipo "Tranco".

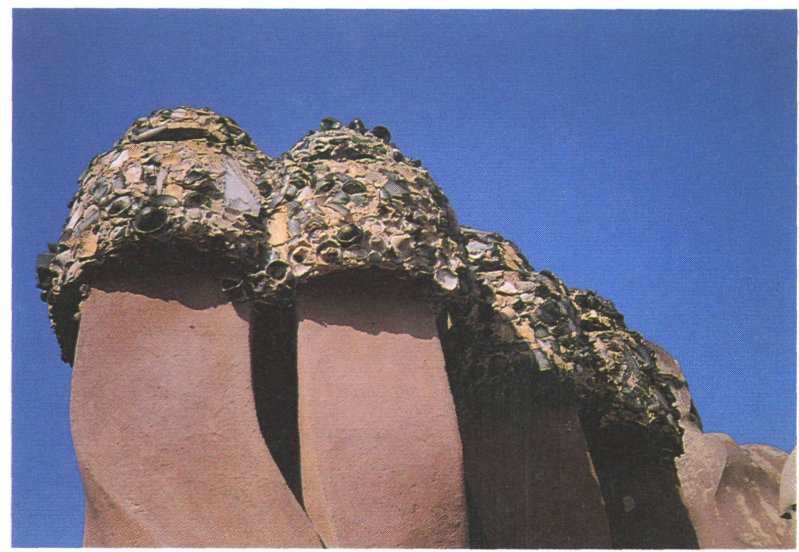

Chimenea $n^{\circ} 16$, de Antoni Gaudi, con revestimiento de fragmentos de vidrio. Estado actual, alzados y plantas, 1992.

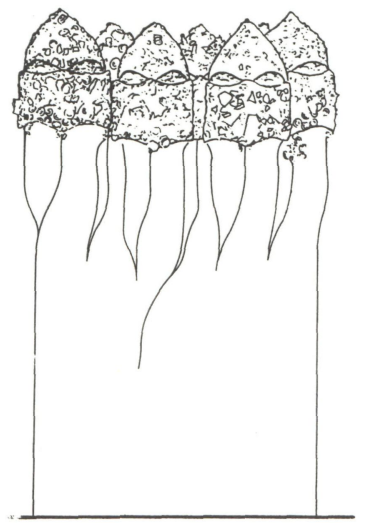

Alzado D

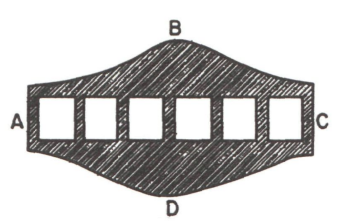

Planta de terraza
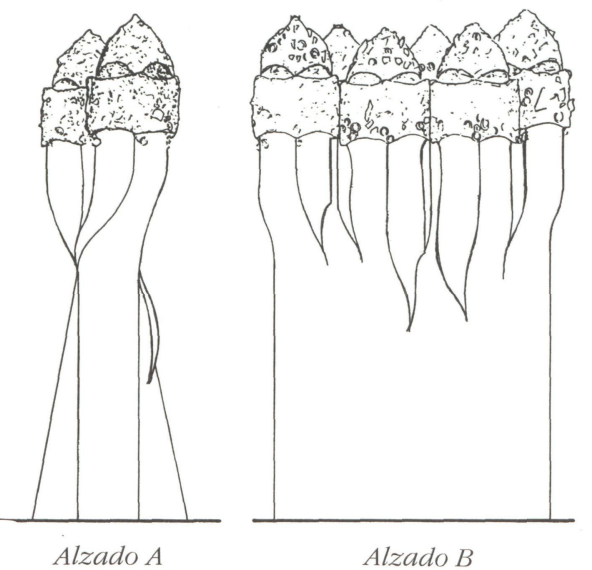

Alzado B

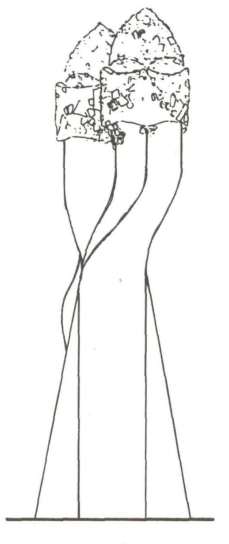

Alzado C

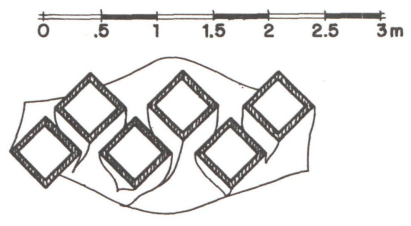

Sección conductos

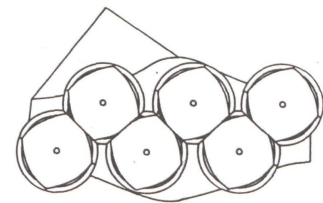

Planta zenital 

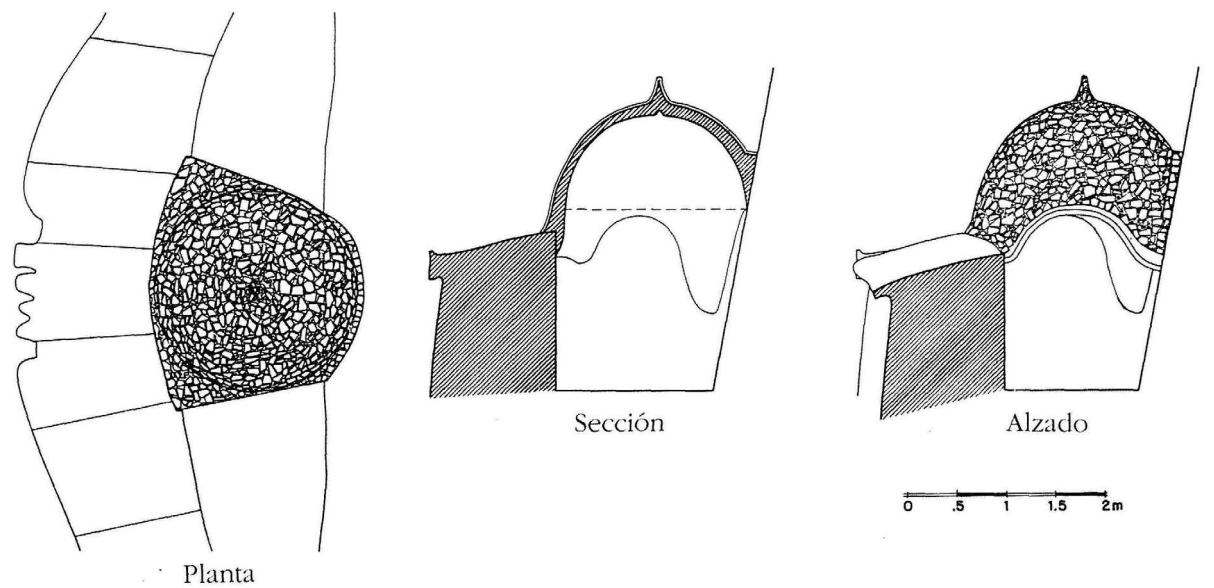

Cupulines situados en el paso de ronda de la planta de los desvanes, que también tienen un revestimiento de "trencadis". Alzado, sección y planta, 1992.

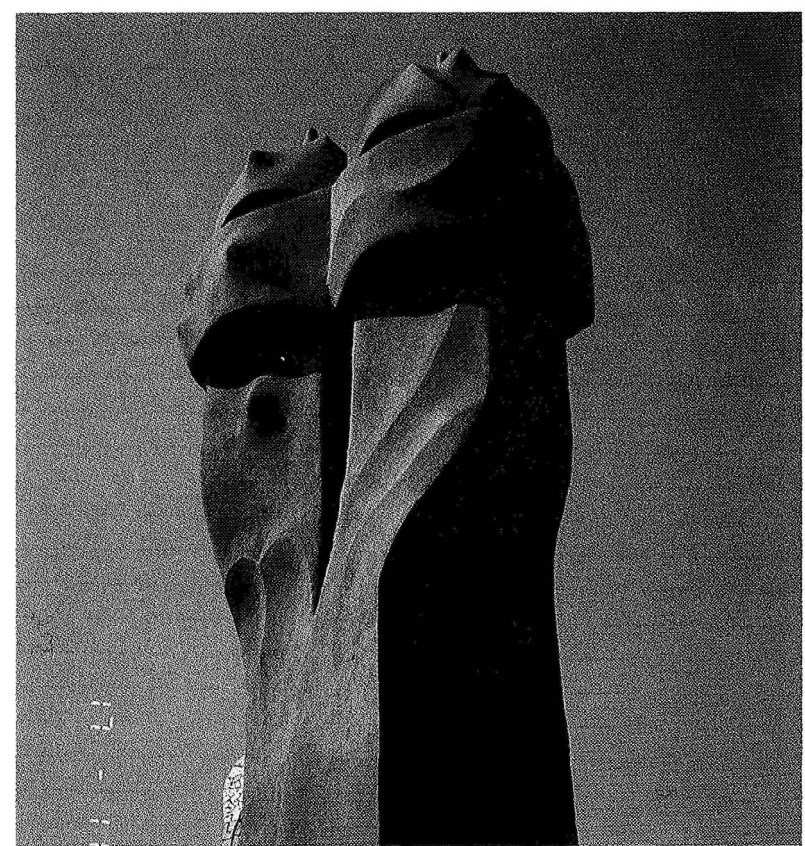

Chimenea no 1, de Antoni Gaudi. Foto: R. Lacuesta, 1992.

se han agrisado y los blancos se han transformado en cremosos o pardo obscuro. Lo mismo ha ocurrido con el revestimiento de la caja de escalera número 4, revestida con los mismos materiales cuyos efectos cromáticos también parecen haberse invertido.

En el caso de la caja $n^{0} 2$, que genera un ritmo helicoidal libre alrededor de una forma cónica virtual, el revestimiento es de mármol del tipo Carrara y del país y de cerámica de Valencia, en su mayor parte esmaltada blanca, pero también con algunas salpicaduras de tonos pastel. Los dos materiales se combinan en franjas alternas, siguiendo la trayectoria y el movimiento ascensional de las espiras y creando reflejos lumínicos de intensidad diferente. La $\mathrm{n}^{2} 3$, de características semejantes, substituye el mármol por la piedra de Ulldecona, con lo cual la superficie se muestra más rugosa y áspera. Cuando Barba Corsini transformó los desvanes en apartamentos, dos de las nuevas chimeneas que construyó (las que han pasado a la memoria popular como el Niño Jesús protegido por Nuestra Señora, puesto que se las atribuía a Gaudí y siempre se ha insistido en su religiosidad transportada simbólicamente a los edificios), mimetizan, tanto en formas como en materiales, las genuinamente gaudinianas.

Para la restauración de la azotea, uno de los criterios que la propiedad del inmueble pretendía establecer era "liberar" este espacio de cuantos objetos no gaudinianos aparecieran. En el estudio, sin embargo, se propuso la restauración no sólo de los edículos originales de Gaudí, sino también de los originales de Barba Corsini que gozan de buena imagen y equilibrio contextual, eliminando, eso sí, todos aquellos que estorban la vista del fantástico paisaje escultórico y que coinciden, además, con ser los peor construidos y los menos agraciados.

Respecto a los elementos que presentan revestimientos pétreos, cerámicos o de vidrio, se propuso consolidar los materiales conservados y, con los mismos materiales y texturas, rellenar las lagunas y substituir los fragmentos deteriorados. En cuanto a las torres, chimeneas y cajas de escalera que no están revestidas, se propuso devolver la textura y el color del acabado final original, es decir, de los enlucidos, tomando como modelo los que aún se conservan en los patios del edificio, para conseguir y completar así la secuencia cromática y de materiales que sin duda Gaudí había proyectado intencionadamente.

Las obras de restauración de la azotea de la Casa Milà, está previsto llevarlas a cabo en 1995. 